\title{
Nuevas percepciones de la historicidad en la novelística contemporánea de América Latina
}

\author{
Claudio Maíz ${ }^{1}$ \\ Facultad de Filosofía y Letras, CONICET, \\ Universidad Nacional de Cuyo, Mendoza, Argentina
}

\begin{abstract}
Resumen: Luego de una breve revisión estado de la cuestión en torno a la conciencia histórica reciente y algunas de sus narrativas nos ocupamos de un abordaje en torno a la pregnancia de la historicidad en otros moldes genéricos latinoamericanos recientes. Para ello se hace necesaria la revisión de algunas categorías de la narratividad, tales como el tiempo, el personaje y la memoria. Ha habido una emergencia de nuevas percepciones del pasado que, a nuestro modo de ver, se formalizan de manera radicalmente diferente, a punto tal que permite dar por cerrado el ciclo de la llamada Nueva Novela Histórica.
\end{abstract}

Palabras clave: Historicidad; Novela; Ficción; Experiencia.

Título: Novas percepções da historicidade no romance contemporâneo da América Latina

Resumo: Logo de uma breve revisão estado da questão em torno da consciência histórica recente e algumas de suas narrativas nos ocupamos de uma abordagem em torno da pregnância da historicidade em outros moldes genéricos latino-americanos recentes. Para isso, se faz necessária a revisão de algumas categorias da narratividade, como tempo, personagem e memória. Podemos constatar uma emergência de novas percepções do passado que, em nosso modo de ver, são formalizadas de maneira radicalmente diferente, a ponto tal que permite dar-se por encerrado o ciclo do chamado Novo Romance Histórico.

Palavras-chave: Historicidade; Romance; Ficção; Experiência.

Title: New perceptions of historicity in the contemporary novelistic of Latin America

Abstract: After a brief state review of the issue around recent historical awareness and some of its narratives, we deal with an approach around the pregnance of historicity in other recent Latin American generic molds. For this, it is necessary to review some categories of narrativity, such as time, character and memory. There has been an emergence of new perceptions of the past that, in our view, are formalized in a radically different way, to the point that allows the cycle of the so-called New Historical Novel to be closed.

Keywords: Historicity, Novel, Fiction, Experience.

1 Doctor en Letras. Facultad de Filosofía y Letras, Universidad Nacional de Cuyo-UNCuyo. Orcid: https://orcid.org/0000-0001-5312-374X

E-mail: cmaiz@ffyl.uncu.edu.ar 
"El recuerdo histórico no es una reserva estática de significaciones definitivamente consignadas en los archivos del tiempo. La actividad de la memoria surge del deshacer y rehacer de los procesos de evocación y narración del pasado a los que nos convocan las solicitaciones políticas y comunicativas de un presente curioso, o bien disconforme." (RICHARD,

2007, p. 197)

A fin de sopesar la dimensión de los cambios ocurridos desde el surgimiento de la novela histórica durante el siglo XIX a las nuevas percepciones de la historicidad en la narrativa latinoamericana más reciente, es preciso destacar la naturalidad con la que la historia, el nacimiento de los Estados nacionales y la identidad (en singular) constituyeron un nudo paradigmático. Entre ambos extremos indicados se ubica la llamada Nueva Novela Histórica que sustituyó ese paradigma por otro en el que se impusieron nociones como la memoria, la reescritura de textos historiográficos y el afán por dar cuenta de las diversidades. Mientras en el primer momento de la novela histórica la memoria era regulada y hasta administrada por el Estado, en el segundo, esa facultad queda en manos de la ficción y la libertad imaginativa. La pregunta que debemos hacernos es qué ocurrió en el ecosistema en el que se han venido desenvolviendo las literaturas de distintos países latinoamericanos y que revelan un cambio sustantivo respecto de la conciencia histórica.

Rápidamente podemos decir que la irrupción del posmodernismo fue algo así como la llegada de un minucioso registro de defunciones. Todas ellas hijas de la muerte primera, declarada por Nietzsche: la muerte de Dios. A la gran orfandad moderna le siguieron las posmodernas representadas por "la muerte del autor" (BARTHES), del "fin de la historia" (FUKUYAMA), "la muerte de los grandes relatos" (LYOTARD). Las muertes declaradas, con el vertiginoso paso del tiempo, dejaron de ser cadáveres sólidos para convertirse en "líquidos" (BAUMAN) o en "gaseosos" (BERMAN). La licuación, pues no fue destrucción, desmoronamiento ni caída, fue tan veloz como fulminante. Casi sin solución de continuidad habíamos pasado de "Funes el memorioso" (BORGES) a la "lógica del zapping" (SARLO). Este somero trazado de la curva que va de la modernidad a la posmodernidad no es un aporte al debate sobre cómo ser posmodernos en América Latina sin haber alcanzado aún las promesas de la modernidad. Convenimos con Fredric Jameson cuando describe la época en la que vivimos como una "[...] época en la que la forma que adopta la ideología dominante es la de un pensamiento del fin de todas las cosas sin que se prevea el comienzo de ninguna: la declamada 'muerte de la historia' es la promoción de una horizontalidad sin horizonte, de una planicie sin accidentes [...]" (JAMESON, 1991, p. 7). A su vez, Esther Díaz caracterizó nuestra época como "póstuma". Ya se sabe que el término significa "después de la muerte". Estamos situados a continuación de los finales, que no se agotan en los que nosotros acabamos de enumerar, sino que se incrementan con otros que Esther Díaz nos recuerda: el fin de las utopías y la constatación de que la teleología histórica no portaba en sus entrañas ni igualdades, paz perpetua o emancipaciones. Todas ellas promesas modernas, cuyo destino 
final fue otro muy diferente. Dos certezas implosionaron en distintos tiempos, una, vinculada con el pasado como la estructura sobre la cual la antigüedad descansó y la otra, la confianza en el futuro en la que la modernidad encontró el nuevo punto de apoyo. La metafísica moderna del progreso acabó en una simultaneidad temporal que subsume diversas temporalidades. De manera que ni la metafísica del progreso ni la racionalidad científica salieron indemnes de los relativismos posmodernos. Junto con el muro de Berlín cayó también la veneración de las ideologías que dejó al descubierto subjetividades fragmentadas, éticas y estéticas precedidas por el prefijo "pos". Tal como lo resume Esther Díaz: "Nuestro tiempo es póstumo porque sobrevive a las categorías político-culturales que lo hicieron posible." (DIAZ, 2012). Esta ajustada crónica inicial conforma un friso dentro del cual hallar explicaciones a cambios que afectaron nociones como la memoria, la experiencia, el protagonismo y la escritura de la novela de materia histórica.

Ahora estamos en condiciones de enmarcar la siguiente cita del escritor peruano Diego Trelles Paz de su prólogo a la antología de relatos, El futuro no es nuestro (2008), en el marco conceptual que antecede:

\footnotetext{
No se habla aquí, desde luego, de una renuncia al pasado histórico como tema literario. En absoluto. Lo que ha cambiado es la forma y, ante todo, esa aspiración fundacional del narrador por legitimar, o deformar, un origen que, en nosotros, ya no es vital. Ni las raíces ni las tradiciones, menos aún conceptos tan desfasados como la nacionalidad o la patria, limitan ahora nuestro pacto incondicional con la ficción. De la misma manera, ya no resulta descabellado o poco serio abordar estos mismos temas históricos (de próceres y dictadores, conflictos armados y revoluciones) mediante géneros antes menospreciados por su carácter formulaico y su arraigo popular, como el policial o la ciencia ficción. (TRELLEZ PAZ)
}

Trelles extrae algunas conclusiones que se vinculan con nuestro tema. En primer lugar, no hay un desentendimiento con el pasado, sino la renuncia a categorías carentes de validez fundacional, como el origen, las raíces, la patria o la nacionalidad. Cuestionable o no, lo que hacemos es comprobar el síntoma. La declinación de esas ontologías da lugar a géneros hasta hace un tiempo considerados "menores" como el policial y la ciencia ficción. De aquel contexto conceptual trazado surge además la distorsión o confusión entre lo histórico y lo ficcional que da lugar a historias alternativas a fin de compensar las deficiencias de la historia occidental. En ese orden, cabe agregar que las metaficciones historiográficas (HUTCHEON, 1989) neutralizan la consagrada oposición entre representación histórica y representación ficcional, exhiben la naturaleza discursiva e intertextual del pasado y de los hechos históricos, construidos como tales por la misma narración (BARTHES, 1967, p. 30-31).

Este escueto estado de la cuestión en torno a la conciencia histórica reciente y algunas de sus narrativas nos permiten ensayar un abordaje en torno a la pregnancia de la historicidad en otros moldes genéricos latinoamericanos recientes. Para ello se hace necesaria la revisión de algunas categorías de la narratividad, tales como el tiempo, el personaje y la memoria. Ha habido una emergencia de nuevas percepciones del pasado que, a nuestro modo de ver, se formalizan de manera radicalmente diferente, a punto tal que 
permite dar por cerrado el ciclo de la llamada Nueva Novela Histórica. Un fenómeno literario que supo captar la atención de la crítica literaria, la filosofía y la misma disciplina histórica. Cuando apelamos al término pregnancia lo hacemos en el sentido de una estética del arte, en la que toda situación de un sujeto se experimenta en un recorte que lo incluye. La pregnancia alude a posibilidades todavía no develadas en su totalidad. Se trata de una combinación de algo aun inexistente, pero también cubierto de probabilidad gracias a la imaginación. Si preferimos el concepto de pregnancia es porque pretendemos diferenciar cierta novelística reciente de aquella que hizo de la materia histórica el centro de interés para el tratamiento narrativo.

\section{Tiempo y protagonismo}

En consonancia con John Lewis Gaddis, en su libro El paisaje de la historia, pensamos el presente "como una singularidad a través de la cual tiene que pasar el futuro para convertirse en pasado." (GADDIS, 2002, p. 53). Dicho de otro modo, no habría futuro ni pasado sin una espera y sin un recuerdo. La conciencia histórica que percibimos en la narrativa reciente muestra al sujeto inmerso en una encrucijada multitemporal, plena de potencialidades, aunque no necesariamente de realizaciones garantizadas. Algunas novelas de pregnancia histórica, a las que nos referiremos, transitan a través de estructuras temporales que se ubican no muy lejos del triple presente agustiniano: "presente de las cosas pasadas, presente de las cosas presentes y presente de las futuras." (AGUSTIN, 2006, $\mathrm{XI}, 20,26$, p. 333). Paul Ricoeur al reflexionar sobre la triple noción, la especifica de la siguiente manera. El presente del pasado se corresponde con la memoria; el presente del futuro con la espera y el presente del presente con la intuición (RICOEUR, 2004, p. 85).

En ese tejido reflexivo, Ricoeur introduce una distinción entre impronta y huella. La primera pertenece al cuerpo en el "nivel cortical" por tanto es del orden de la naturaleza, mientras que la huella es de orden fenomenológico, construida sobre la base del "serafectado por el acontecimiento del que se da testimonio por narración" y agrega a continuación algo de mucho valor para nuestra argumentación, a saber, el testimonio sobreviene tras la modificación -dice Ricoeur- de las experiencias pasadas en función de las nuevas (RICOEUR, 2004, p. 93). El filósofo percibe que la alteración se hace factible después de romperse el "pacto de la memoria con el pasado en beneficio de una escritura íntima en un espacio imaginario", de modo tal que la imaginación ocupa el lugar de la memoria (p.93). En rigor, tanto la novela como la historia comparten el uso de la imaginación, las diferencias se revelan en el grado de vigencia del "pacto de la memoria con el pasado". La inestabilidad del pacto con el pasado, afecta también otra dimensión, como la relación con el futuro. Con el irónico título, "Dinamitar la propiedad ajena", el escritor mexicano Naief Yehya dice en la introducción a la antología de Diego Trelles Paz: "El futuro se parece al presente, pero como no es nuestro, nada mejor que ponerle una bomba y disfrutar el espectáculo pirotécnico." 
(YEHYA, 2008).

Con todo, se sabe que las subjetividades en América Latina están atravesadas por la temporalidad occidental. Las concepciones del tiempo que la cultura europea introdujo fueron incorporadas y experimentadas como propias. A partir de esas percepciones del tiempo se han organizado los registros de los sucesos acontecidos o lisa y llanamente la historicidad de las comunidades latinoamericanas. Se ha dado forma al pasado de acuerdo con recortes que se aceptaron como válidos. Pero nadie puede ignorar que la filosofía occidental del tiempo no es la única existente, ni menos la excluyente en América Latina. El historiador y mucho menos el novelista debería ignorar la convivencia de las multitemporalidades ya aludidas como tampoco aquellas que se corresponden a los procesos de occidentalización de América Latina que se configuran de acuerdo a la linealidad progresista en desmedro de la temporalidad cíclica y de larga duración del mundo indígena (OCAMPO LÓPEZ, 1986, p. 402).

No obstante, en la novela el pacto con el pasado tiende a ser inestable o en otros casos prescindente. El colombiano William Ospina ha manifestado recientemente, a propósito de su nueva novela Guayacanal (2019), que se trata de una "historia de hechos que ocurrieron" pero como la memoria opera selectivamente, eso provoca que "lo que fue realidad termine siendo ficción." Son de valor estas declaraciones ya que provienen de un novelista que ha escrito una trilogía sobre la conquista a través de figuras históricas como Pedro de Urzúa, Francisco de Orellana, Gonzalo Pizarro, entre 2005 y 2012. Sin embargo, en Guayacanal, Ospina da un giro rotundo al dejar de ocuparse de "personajes ilustres", y recuperar seres anónimos, "los que construyen los países" -dice-, y además "hacen la historia" (OSPINA). El novelista colombiano Pablo Montoya, en papel de crítico literario, analiza la novela Historia secreta de Costaguana de otro colombiano, Juan Gabriel Vásquez. Según Montoya, Vásquez privilegia la libertad para modificar las cronologías y escenarios que faciliten la destrucción de las causalidades, tan propios de la novela histórica realista (MONTOYA, 2009, p. 87). Gracias a la distorsión, según Montoya, Vásquez visibiliza, en la imaginación del lector, "lo que antes eran datos de libros de historia", como por ejemplo "la construcción del ferrocarril de Panamá y el fracaso en la primera fase de la construcción del canal y las guerras intestinas" (MONTOYA, 2009, p. 94). Este procedimiento es productivamente renovador de la narrativa de materia histórica flamante, ya que devela tanto lo oculto como lo deliberada o convenientemente olvidado. Para ello no es necesario que los personajes heroicos lleven adelante tamaña faena, sino que Vásquez se apoya en un "simple personaje secundario al que le asigna "un elevado estatuto en el ámbito de la ficción" (MONTOYA, 2009, p. 94). Merced a lo cual, la novela enfrenta la "aplastante realidad colombiana" (MONTOYA, 2009, p. 95). En el otro extremo se sitúa William Ospina, según Montoya, ya que el autor de Urzúa está más preocupado por el lenguaje poético que por la ruptura de las causalidades. Esta diferencia pone a Vásquez en el plano de la imaginación libérrima y a Ospina recostado en referentes de procedencia historiográfica, como Juan de Castellanos, Cieza de León, Gonzalo Fernández de Oviedo (MONTOYA, 2009, p. 108). La 
novela, en consecuencia, se aparta de "anacronismo, burlas o parodias" (MONTOYA, 2009, p. 109).

Otro rasgo sobresaliente que procede de los movimientos del actante histórico es la acentuada pérdida del aura y el sitial incuestionable del héroe (a decir verdad, esto ocurrió, en general, con el surgimiento de la novela moderna). De tal modo se produce un reordenamiento de la relación del individuo, el pasado y la escritura, en virtud de que el desplazamiento del héroe hizo que el sujeto sin atributos épicos regresara con mayor fuerza y protagonismo, aunque representando en el curso del relato una función más paciente que activa. La historia lo invade y hasta destruye su trayectoria vital. Sin adentrarnos demasiado en la problemática de una "privatización de la historia", digamos que una distinción entre héroe, antihéroe y meta-héroe puede auxiliarnos en la indagación de las implicancias de estos cambios del personaje en la novela contemporánea latinoamericana, cuyos matices o torsiones merecen una detenida constatación. Afirmar que ha concluido la vigencia de la Nueva Novela Histórica, cuya radical característica consistió en reescribir la historiografía oficial, y de esa manera sacudir los cimientos de la identidad nacional, coloca a la crítica en la necesidad de ahondar en la historicidad que se infiltra, mediante nuevos recursos, en la narrativa actual. Una afirmación como la anterior no cierra de ninguna manera el debate sobre la naturaleza discursiva del constructo llamado relato genealógico de la nacionalidad, al contrario, se abre en un nuevo abanico de posibilidades.

Ahora bien, la elaboración épica, es decir, los relatos que ensalzaban figuras tan triunfantes como grandiosas, ha sido una perspectiva que la literatura mundial le ha cedido desde hace tiempo a la cinematografía. En efecto, el cine es el verdadero realizador de una épica que resulta a veces candorosa, aunque entretenida, debido a sus notas estereotipadas y previsibles. La ficción narrativa contemporánea, en cambio, ha seguido un proceso en el que la degradación del espíritu épico se ha ido dando paulatina e ininterrumpidamente. Las resoluciones triunfantes, exitosas o didácticas en una trama novelística cesaron hace mucho tiempo. El devenir de esta alteración ha ido de un pasado absoluto del héroe épico (BAJTíN, 1989, p. 547) a una imagen del hombre que ingresa a una dimensión de contacto con un presente inacabado. En otros términos, el protagonista es "alguien como nosotros" como propuso el realismo. El personaje heroico se volvió definitivamente inviable con el poder corrosivo de la ironía posmoderna, que descompuso al héroe con el uso de la parodia al extremo del patetismo y la ridiculez.

El cambio en la figura del héroe es concomitante con el eclipse de las utopías. El desencanto, el sentimiento de la derrota, el cinismo o la resistencia son algunas de las nuevas investiduras que adquiere el personaje en las novelas actuales. Resultan entonces verdaderas "instrucciones para la derrota" (AMAR SÁNCHEZ, 2010). Autores como Horacio Castellanos Moya, Leonardo Padura, Rodrigo Rey Rosa, entre otros, dan cuenta de ello. La particularidad que presenta la novelística de estos autores es que registran un sentimiento de indignación, desazón o escepticismo ante traumas profundos que han experimentado las sociedades de las que provienen. Experimentan una multitemporalidad compuesta por un 
presente arruinado, un pasado reciente luctuoso y un futuro obturado. Los autores no se esfuerzan por traspasar esta plataforma donde están asentados. En efecto, la noción tradicional de personaje con un trayecto vital que se configura a lo largo del texto se ha visto afectada por una des-subjetivación, en algunos casos o en una re-configuración identitaria, en otros. El albañil Juan Roa Sierra es el tortuoso protagonista de la novela del colombiano Miguel Torres, El crimen del siglo (2006). La novela está contada desde la perspectiva de un individuo, cuya única acción sobresaliente fue disparar el viernes 9 de abril de 1948 contra Jorge Eliécer Gaitán, el líder popular del Partido Liberal.

Aquel requisito del lapso de cincuenta años de Lukács para la novela histórica también ha perdido vigencia. Si la distancia temporal con el hecho histórico era un condicionamiento para embarcarse en la creación novelesca, la nueva narrativa de pregnancia histórica no se ajusta ni aviene a esa exigencia. La estructura temporal se ajusta a una idea tridimensional, habida cuenta de la multitemporalidad experimentada por el narrador y trasladada al relato. Haberse liberado del requisito de que para tratar la materia histórica el autor no debía haber pertenecido a ese tiempo abrió el camino para llevar adelante novedosas combinaciones temporales. Así el caso de la novela Cadáver tuerto del chileno Eduardo Labarca (2005). La novela se encuentra a más de treinta años de la década del Golpe Militar y su escritura es casi contemporánea a los hechos, va de los de años 1970 a la detención del dictador Augusto Pinochet entre 1998 a 2000 (BARRAZA, 2010, p.100).

\section{Intrahistoria: un protagonista "como nosotros"}

La figura protagónica de las novelas que ficcionalizan la materia histórica desde la Novela Histórica Tradicional hasta las novelas de asunto histórico más cercanas, pasando, por la denominada Nueva Novela Histórica, se vio alterada estructuralmente. Uno de los cambios que se advierte es una variación de la centralidad del personaje histórico protagónico, que va de ser un actante apenas referido a ocupar el primer plano, como en la Nueva Novela Histórica. Pero ahí no se detuvo la transformación, sino que tuvo una vuelta más al abandonarse el protagonismo heroico para promover al centro de la trama de la ficción histórica un individuo "como nosotros", similar al del realismo, como se dijo.

La experiencia multitemporal del presente afecta al narrador, pero también esta afectación recae en los personajes anónimos, singulares, aquellos que en ciertos casos ignoran que la historia conduce sus vidas. La experiencia es singular pero no siempre consciente. Quizás en ello reside la razón para Walter Benjamin, el "núcleo temporal de la historia no se deja aprehender como algo que ocurre propiamente y que se extiende en la dimensión real del tiempo, sino allí donde el desarrollo se detiene durante un instante" (TIEDEMAN, 2005, p 27). De esos instantes singulares, en los que el curso del tiempo se ha detenido, se ocupa la narrativa más cercana, ya sea como fósil, fetiche, imagen del deseo o ruina (BUCK-MORSS, 2001). Nuevamente nos remitimos a Gaddis para decir que, si se 
"piensa que el pasado es un paisaje, la historia es la manera como lo representamos, y es justamente este acto de representación lo que nos eleva por encima de lo familiar para permitirnos tener experiencias sustitutorias de lo que no podemos experimentar directamente: una visión más amplia." (GADDIS, 2002, p. 21). Experiencias singulares dentro de visiones dilatadas constituye otra nota distintiva actual.

A la luz de los cambios señalados, los nuevos modos de textualizar la conciencia histórica imponen detenerse en cuestiones fundamentales, que las podemos expresar en forma de interrogantes: ¿Cómo se configura la historicidad de un individuo? ¿Cuáles son los caracteres que le confieren naturaleza histórica? ¿Cómo se abandona el anonimato? Estas preguntas harían presumir una declinación de identidades compartidas o que lo individual adquiere una preeminencia desmedida. En buena medida no estamos lejos de afirmarlo, en consecuencia, se impone al menos como hipótesis la exploración de lo anónimo o en cierto modo lo impersonal. No estamos seducidos por el problema de la representación del referente histórico o extratextual, sino por la constatación crítica del retorno tanto del personaje anónimo como del omitido que se roza con la historia, ya sea para padecerla o caer en sus torbellinos destructivos.

Imagen 1 - Distinciones

\begin{tabular}{|l|l|}
\hline \multicolumn{1}{|c|}{ SUJETO HISTÓRICO } & Neutralidad I pasividad \\
\hline Heroismo & Anonimato \\
\hline Gama & Cautela I indiferencia \\
\hline & Hazañas
\end{tabular}


Una rápida observación de ambas columnas nos da una aproximación a los interrogantes anteriores. La primera columna no solo contribuye al forjamiento del individuo histórico, que alcanza la dignidad de ser investigado y considerado por la historiografía. La segunda columna contiene atributos de individuos sin relevancia cultural, social o política. Sin embargo, en el debate historiográfico, en un determinado momento, esta somera división fue cuestionada y comenzaron a ser atendidos los sujetos de la segunda columna. Fue un vuelco en el interés historiográfico por los seres anónimos. Carlo Ginzburg es un ejemplo de este significativo cambio. En el prefacio a El queso y los gusanos, escribió:

\footnotetext{
Antes era válido acusar a quienes historiaban el pasado, de consignar únicamente las 'gestas de los reyes'. Hoy día ya no lo es, pues cada vez se investiga más sobre lo que ellos callaron, expurgaron o simplemente ignoraron. '¿Quién construyó Tebas de las siete puertas?' pregunta el lector obrero de Brecht. Las fuentes nada nos dicen de aquellos albañiles anónimos, pero la pregunta conserva toda su carga. (GINZBURG, 1999, p.3).
}

El giro trasladó la escritura historiográfica de los campos de batalla a la intimidad de los hogares, de las decisiones regias, presidenciales o militares a las vidas privadas, incluyendo las mujeres antes vistas como satélites de los hombres para ser visualizadas en un papel relevante.

Surgen de ese modo tendencias a reincorporar voces marginalizadas en un discurso sobre el pasado y de "integrar las perspectivas a nivel microhistórico" que se acompañan de un cambio generacional (CICHOCKA, 2012, p. 32). Hay un desplazamiento de la historia de los acontecimientos a la historia de larga duración, historia de las mentalidades, historia de las minorías. Es una manera novedosa de visualizar el pasado por medio ya no de los personajes descollantes sino de la llamada "microhistoria" o "historia desde abajo". El archivo cobra un nuevo valor y su expurgación minuciosa puede brindar el detalle que no fue considerado, a partir del cual es factible la reconstrucción de cuadros más complejos de una época y su mentalidad. "Un paso más y nos encontramos en la frontera entre la disciplina historiográfica y la creación literaria, y un texto que reescribe la historia de los personajes anónimos y de sus vidas privadas torcidas por la historia colectiva: la llamada novela intrahistórica." (CICHOCKA, 2012, p. 33). El tránsito de la existencia a la palabra pasando por la experiencia del sujeto de la primera columna, la que provisoriamente vinculamos con el sujeto histórico, entendido como el sujeto de la historiografía, podría constar de los siguientes estadios: 
Imagen 2 - Estadios

\begin{tabular}{|c|c|c|c|c|}
\hline HUMANO & $\begin{array}{l}\text { ACCIONES } \\
\text { REALIZADAS }\end{array}$ & TESTIMONIOS & SOPORTES & REPRESENTACIONES \\
\hline $\begin{array}{l}\text { Existencia de } \\
\text { un individuo } \\
\text { que, aunque ha } \\
\text { dejado de } \\
\text { existir, la } \\
\text { prueba de que } \\
\text { alguna vez } \\
\text { vivió se } \\
\text { encuentra en la } \\
\text { documentación } \\
\text { probatoria de } \\
\text { su nacimiento } \\
\text { y muerte. }\end{array}$ & $\begin{array}{l}\text { Conjunto de } \\
\text { acontecimientos } \\
\text { en los que el } \\
\text { individuo } \\
\text { participa de } \\
\text { manera decisiva } \\
\text { en hechos que } \\
\text { trascienden los } \\
\text { ámbitos } \\
\text { privados y } \\
\text { cuyos } \\
\text { compartimientos } \\
\text { no son ni } \\
\text { comunes ni } \\
\text { ordinarios. Hay } \\
\text { potencia } \\
\text { transformadora. }\end{array}$ & $\begin{array}{l}\text { La procedencia } \\
\text { de los } \\
\text { testimonios } \\
\text { varía: las del } \\
\text { actor que } \\
\text { realiza los } \\
\text { hechos } \\
\text { inusuales; la } \\
\text { de terceros } \\
\text { que la } \\
\text { corroboran; } \\
\text { memorias } \\
\text { colectivas; } \\
\text { periódicos, etc }\end{array}$ & ARCHIVOS & $\begin{array}{l}\text { Punto álgido de todo lo } \\
\text { precedente. "Aparece" } \\
\text { la escritura, cuya } \\
\text { función es decisiva. } \\
\text { Desde la mimesis } \\
\text { aristotélica a la } \\
\text { superestructura } \\
\text { marxista, en esta } \\
\text { cuestión se dirimen las } \\
\text { disputas sobre el signo. }\end{array}$ \\
\hline
\end{tabular}

La novela histórica realista admitió que el "referente histórico" estaba constituido por el protagonista historiográfico, por lo que se ajustaba a él de manera paralela y lo continuaba. El "referente histórico" se prolongaba en el argumento novelesco. La nueva novela histórica continuó dándole crédito a ese sujeto de la historiografía, aunque desde una perspectiva en la que lo reinventaba, mediante recursos, entre otros modos, como la parodia. La conciencia histórica contemporánea si se apoya en una figura de la historia lo hace para abrir camino al protagonismo del sujeto que la historiografía no consideró digno de destacar con el detalle y despliegue del sujeto histórico protagonista. En resumen, sin referente histórico, con la recuperación de sujeto semi anónimo o anónimo, ¿cómo se configura aquella conciencia histórica contemporánea? Mantener la distinción entre un discurso y otro no resuelve la incógnita: la narrativa de la historia y la narrativa literaria comparten procedimientos, estrategias, técnicas. La imaginación no es dominio exclusivo de la literatura; existe también una imaginación histórica. El discurso historiográfico es inexistente sino está configurado en un relato y una trama. Una lingüística estructural del discurso, dice Barthes, no puede ya conservar antiguas tipologías. Aun reconociendo la legitimidad de la oposición entre discurso poético y discurso novelesco, entre relato ficticio y relato histórico, se detiene en esta última oposición para preguntarse si la narración de acontecimientos pasados sancionados por la "ciencia" histórica, "¿difiere realmente, por algún rasgo específico, por alguna indudable pertinencia, de la narración imaginada, tal como la podemos encontrar en la epopeya, la novela, el drama? (BARTHES, 1987, p. 164). Sin admisión del "referente" extratextual, con un creciente como intenso desbordamiento de los campos entre la historia y la literatura a través de la narración, ¿de dónde procede la materia histórica novelada en la literatura contemporánea? Como escribió Seymour Menton para el caso de la Nueva Novela Histórica, de la "influencia de algunas ideas filosóficas, como por 
ejemplo la imposibilidad de conocer la realidad o la verdad histórica" (MENTON, 1993, p. 42 46). O mucho antes, cuando la Novela Histórica Realista se ajustaba al dato histórico. Pero Jameson irá aún más lejos al sostener que nos resta solo "representar" nuestras ideas y estereotipos sobre ese pasado (que se convierte por ello, de inmediato, en "historia pop") (JAMENSON, 1991, p. 46). Ni referente ni influencia filosófica, sino que ahora son los estereotipos sobre el pasado. Tal la razón por la cual el crítico marxista considera que no hay lugar para la parodia puesto que no hay modelo sólido que parodiar.

No obstante, lo dicho es parte de la respuesta acerca de lo que abastece a la novela de materia histórica actual. Queda por ver hasta dónde la noción de intrahistoria retorna como estrategia narrativa en algunos desplazamientos literarios actuales. En estrecha relación con la visión polifónica del pasado de la que habla Marta Cichocka se halla la noción de intrahistoria. Este concepto, acuñado por Miguel de Unamuno ${ }^{2}$ es retomado por Luz Marina Rivas, quien nombra como un subgénero a lo que llama "novela intrahistórica". Rivas habla asimismo de consciencia de la historia. Los requisitos de esta conciencia se regirían a través de los siguientes parámetros:

- problematizar la historia en el texto ficcional, a fin de proponer una mengua de la pretendida potencia de la verdad histórica.

- cuestionar registros históricos, el documento como fuente, dudar de los archivos, todo ello dentro del marco de la ficción.

- dialogar intertextualmente con textos históricos conocidos, o apropiarse de lenguajes alternativos para contar la historia, como mitos, testimonios, narraciones orales, etc. (RIVAS, 2001, p. 107)

Esta conciencia de la historia ha Estado presente en las novelas que han confrontado la historia oficial, escrita y ordenada desde el poder. Pero también esa conciencia se ha hecho presente asentada en perspectivas diferentes, como mirar los hechos históricos "desde abajo", prestar atención, dice Rivas, a "la historia de las víctimas, de los ciudadanos comunes y anónimos, de testigos marginales." (RIVAS, 2001, p. 107). Es la historia de las gentes desconocidas, sin las cuales las grandes empresas políticas y militares no serían posibles. (RIVAS, 2001, p. 107). La "novela intrahistórica" se abastece de personajes marginados, sujetos anónimos. Recurre al uso del testimonio, la oralidad, el dialogo epistolar, el diario, archivos ignorados, entre otros elementos.

Por lo expuesto, la conciencia histórica no es otra cosa que una textualización, es

\footnotetext{
${ }^{2}$ Escribe Unamuno en su ensayo En torno al casticismo: "Todo lo que cuentan a diario los periódicos, la historia toda del "presente momento histórico», no es sino la superficie del mar, una superficie que se hiela y cristaliza en los libros y registros, y una vez cristalizada así, una capa dura, no mayor con respecto a la vida intra-histórica que esta pobre corteza en que vivimos con relación al inmenso foco ardiente que lleva dentro. Los periódicos nada dicen de la vida silenciosa de los millones de hombres sin historia que a todas horas del día y en todos los países del globo se levantan a una orden del sol y van a sus campos a proseguir la oscura y silenciosa labor cotidiana y eterna, esa labor que como la de las madréporas suboceánicas echa las bases sobre que se alzan los islotes de la historia." (UNAMUNO, 2007, p. 80)
} 
decir, "una objetivación visible en el texto de la novela", pero provista más de nuestros estereotipos que de hechos históricos. Tales estereotipos pueden ser compartidos entre autor y lector. Dicho en otros términos: "[...] el referente histórico se asocia frecuentemente con la dimensión metahistórica, a través del discurso sobre la historia, la memoria, el tiempo y el olvido, y las maneras de trasmitir el pasado." (CICHOCKA, 2012, p. 29)

\section{Configuración imaginaria del dato histórico y la ruina}

En la Novela histórica tradicional como narración omnisciente el "efecto histórico" se obtiene combinando verosimilitud y didactismo que sostiene la base documental de la novela. La novela histórica moderna mantiene el respeto hacia los datos históricos, pero los maneja con una perspectiva muy distante de la tradicional, ya que subjetiviza la historia al trasmitir el pasado desde la interioridad de los personajes o desde el filtro moral e ideológico del narrador (Vargas Llosa, El sueño del celta, 2010). La llamada Nueva Novela Histórica o la novela histórica posmoderna, desde la segunda mitad del siglo XX, propone una distorsión del material histórico incorporado a la diégesis ficcional, con propuestas de historias alternativas o apócrifas sobre sucesos o personajes de gran relevancia (Abel Posse, Los perros del paraíso, 1983). En las expresiones más reciente, la multitemporalidad del presente, el anonimato, la experiencia singular, las búsquedas obsesivas (e inútiles) en los archivos dan sustento a la trama narrativa. En tal sentido, la ruina resulta una noción que abre nuevas perspectivas.

¿Qué es la ruina? Nuestra respuesta excede el campo arqueológico, por cuanto la consideramos como regímenes de simultaneidad temporal opacados, desdeñados que nos sitúan más allá de la metafísica del progreso o de los universalismos iluministas que despojaron a la acción humana de la dimensión de los afectos, pasiones y voluntades. En la "Etiología de la histeria" (1896), Freud emprende una analogía entre analista y un explorador, quien se ve atraído por unas ruinas de muros y fragmentos de columnas. Si el explorador se decide a trabajar sobre esos restos, de un muro se reconstruirá un templo, por caso. Freud corona el pasaje con esta expresión latina 'Saxa loquuntur', que significa "el lenguaje de las piedras" (FREUD, 1981, p. 300).

Los 'ars memoriae' constituyen, entre otras cosas, la vía para la reposición de huellas, ruinas, restos ignorados o presumiblemente falseados por la historiografía estatal. Se plantea, como consecuencia, una lucha entre el dato y el relato, el documento probatorio y la construcción imaginativa. Este procedimiento ya había sido utilizado por algunos miembros del boom, como es el tratamiento de "la matanza de Aracatapa" (1928) en la novela de Gabriel García Márquez, Cien años de soledad. La matanza de las bananeras se eleva a 3000 muertos durante la represión, a pesar de que García Márquez ha reconocido que no superaban la decena, sin embargo, el hiperbólico tono de la novela no admitía un número tan menguado de muertos. De suerte tal que la versión garcíamarquiana termina 
imponiéndose como "verdadera". El problema aquí es que el episodio fue silenciado meticulosamente durante mucho tiempo. La exhumación novelesca de un acontecimiento ocultado le deja a la ficción el privilegio de la última palabra.

Algo similar sucede con los hechos de la Escuela Santa María de Iquique (1907), una represión militar contra los obreros del salitre. El escritor chileno Hernán Rivera Letelier escribió Santa María de las flores negras (2002), que se refiere a la matanza de miles de obreros apostados en la Escuela Domingo Santa María, venidos del Desierto de Atacama en protesta por las pésimas condiciones de vida. La huelga desencadenó el uso de la fuerza militar con un saldo de más de tres mil hombres, mujeres y niños. Este número, por supuesto, que está en discusión como el número de muertos en la novela de García Márquez. Ambos episodios nos muestran las tensiones existentes entre ficción y realidad, en el sentido de que hechos de sangre en los que los Estados están comprometidos caen bajo una interdicción, a fin de purificar las bases del relato nacional. La oposición entre la ficción y el Estado no es solo por la relevancia cuantitativa en el ejercicio espurio del poder, sino por la reposición en un relato maestro de aquello que ha sido deliberadamente silenciado, ignorado u oculto.

Dicho de otro modo, en los casos se trata de una violencia que el Estado ejerce a través de sus fuerzas represivas. Los hechos sangrientos y repudiables no tienen cabida en la poética fundacional de la nacionalidad. Todo lo contrario, hay una deliberada política de selección de acontecimientos en el relato identitario. En estos casos son las 'ars oblivionis' que actúan. El camino de los cambios recorrido entonces no es tan largo. Ya no hay una tendencia a reescribir la historia, ya que de esa manera se le admite entidad epistemológica a ese discurso, sino que se procura sondear el pasado a través de intersticios, grietas, fondos sombríos. Los resultados de estas acciones reciben el impulso de las 'ars oblivionis'. El dato histórico ha dejado de ser el centro de la disputa, ya no se pretende rescribirlo, tergiversarlo, reinventarlo o parodiarlo. La centralidad ha girado hacia la ruina, cuyos vestigios deben reconstruirse ante la mudez inherente de la ruina. Hay una enorme diferencia entre lo que Fernando Ainsa llamó "los sistemas celebratorios" de clara representación de una narrativa nacional y, por otro lado, la ruina. El concepto de Ainsa daba cuenta de una nemotécnica visual, discursiva, arquitectónica, monumental, claramente estable pero también selectiva. Son los lugares de la memoria. Fueron instaurados por mandato de un poder para forzar el recuerdo de una genealogía. Todo lo contrario de lo que sucede con la ruina, puesto que coloca a los sujetos en la necesidad de ejercer una acción repositiva de lo que alguna vez estuvo y luego desapareció, aunque ha dejado alguna traza convertida en un protorecuerdo. Restablecer las piezas restantes es una tarea arqueológica en la que la imaginación cumple una función estructurante. Monumento y ruina como ficción y Estado ocupan un mismo campo de disputa, que se nutre de latencia y muerte, revelación y ocultamiento, prueba y denegación sustitución y restitución. Seguimos a Nelly Richard en estas parejas oposicionales. (RICHARD, 2007). El monumento recibe la energía estatal y es el rastro más palmario de una política de la memoria que procura celebrar un linaje. La ruina es un 
conjunto de esquirlas, fragmentos, voces acalladas o susurros que llegaron a serlo no por casualidad sino por el manto de olvido que cubrió en algún momento el episodio capaz de restarle coherencia y credibilidad a la narrativa de un pasado glorioso. Como ha afirmado Biruté Ciplijauskaité: "Lo no dicho de la historia se descubre por colocar fragmentos de lo conocido en contextos nuevos." (CIPLIJAUSKAITÉ, 2001, p. 47). Se trata de hacer "oír los silencios".

Uno de los mejores ejemplos que podemos poner aquí es la novela de Juan Gabriel Vásquez, La forma de la ruinas (2015). El libro se centra en dos magnicidios que anticipan la violencia en la Colombia moderna. En 1914 es asesinado el senador liberal Rafael Uribe Uribe y en 1948, Jorge Eliécer Gaitán, episodio que desata el conocido "bogotazo". A estos episodios colombianos se suma la muerte de Kennedy en Dallas en 1963, el episodio que más sospechas e incredulidades ha despertado. Los hechos criminales fueron atribuidos a ciudadanos anónimos. Un personaje de la novela, Carlos Carballo, descree de las versiones de la historia y echa mano a las teorías conspirativas que según él contrarrestan las versiones oficiales sobre la muerte de Gaitán. Carballo es el personaje obsesionado por encontrar señales que abonen su propia teoría de las muertes. Marco Tulio Anzola es un abogado para quien el asesinato del senador Rafael Uribe Uribe no se trata de un episodio aislado. Personajes que van en busca de las ruinas de la historia para dar crédito a la conspiración en la que creen ciegamente. La sospecha conduce a la paranoia y esta a la obsesión de husmear en los quiebres del relato canónico.

Hemos pretendido presentar algunas variantes en las percepciones de la historicidad propias de algunas narrativas recientes. Las novelas en cuestión ya no se ciñen a la materia histórica, sino que con ella construyen ficciones del pasado, desde la perspectiva de aquellos seres marginados, anónimos o que fueron relegados por el discurso historiográfico. Sin pretender explicar totalmente las razones de los cambios, sugerimos que el rastreo de las huellas del pasado es un esfuerzo por contrarrestar lo que el poder es capaz de ocultar o borrar. Las ruinas que recorren el presente son proporcionales al trauma. Reponer lo que hubo antes de la ruina es parte del camino para elaborar el duelo y la melancolía ante hechos que han golpeado determinadas sociedades. Walter Benjamin propuso una concepción de la historia que bien puede ajustarse a nuestro recorrido, cuando afirma que "articular históricamente el pasado no significa conocerlo 'tal como verdaderamente fue'. Significa apoderarse de un recuerdo tal como éste relumbra en un instante de peligro." (BENJAMIN, 2008, p 40). La monumentalidad heroica ha sido uno de los peldaños para llegar a considerar la significación del detalle y los acontecimientos pequeños que el poder, el Estado o los historiadores han despreciado.

\section{Referencias}

AMAR SÁNCHEZ, A. M. Instrucciones para la derrota. Narrativas éticas y políticas de perdedores. Barcelona: Anthropos, 2010. 
AGUSTIN, S. Confesiones. 1. ed. Buenos Aires: Colihue. 2006.

BARRAZA, E. Para una lectura de Cadáver Tuerto de Eduardo Labarca en el marco de la Novela histórica reciente. Alpha, 30, julio 2010. https://doi.org/10.4067/S0718$\underline{22012010000100007}$

BARTHES, R. El discurso de la historia. El susurro del lenguaje. Más allá de la palabra y la escritura. España: Paidós, 1987.

BAJTíN, M. Problemas literarios y estéticos. Traducción de Helena Kriúkona y Vicente Cazcarra. Madrid: Taurus, 1989.

BENJAMIN, W. Tesis de la historia y otros fragmentos. Edición, traducción e introducción de Bolívar Echeverría. México: UACM, 2008.

BUCK-MORSS, S. Dialéctica de la mirada. Walter Benjamin y el proyecto de los Pasajes. Madrid: A. Machado Libros, S.A., 2001.

CICHOCKA, M. Algunas estrategias de la novela histórica contemporánea desde un rompecabezas temporal hacia una dimensión intrahistórica. Verba hispánica. 20, 2, 2012. https://doi.org/10.4312/vh.20.2.43-59

CICHOCKA, M. Estrategias de la novela histórica contemporánea: Pasado Plural, Postmemoria, Pophistoria. Frankfurt: Peter Lang, 2016. https://doi.org/10.3726/978-3-653$\underline{06382-0}$

CIPLIJAUSKAITÉ, B. Escribir el pasado desde el presente. Estudios. Revista de Investigaciones Literarias y Culturales, n. 18, 2001.

DIAZ, E. Revista Ñ, 14 de julio de 2012. Disponible en: https://www.estherdiaz.com.ar/textos/epoca postuma.htm

FREUD, S. Etiología sobre la histeria. Obras Completas. Tomo I. Traducción de Luis LópezBallesteros y de Torres. Madrid: Biblioteca Nueva, 1981.

GADDIS, J. El paisaje de la historia. Cómo los historiadores representan el pasado. Traducción de Marco Aurelio Galniarini. Barcelona: Anagrama, 2002.

GINZBURG, C. El queso y los gusanos. El cosmos, según un molinero del siglo XVI. Traducido del italiano por Francisco Martí. Barcelona: Muchnik, 1999.

JAMESON, F. Ensayos sobre posmodernismo. Traducido por Esther Pérez, Christian Ferrer y Sonia Mazzco. Compilado por Horacio Tarcus. Buenos Aires: Ediciones Imago Mundi, 1991.

MENTON, S. La nueva novela histórica de la América Latina 1979-1992. México: Fondo de Cultura Económica, 1993.

MONTOYA, P. Novela histórica en Colombia, 1988-2008: Entre la pompa y el fracaso. Medellín: Editorial Universidad de Antioquia, 2009.

OCAMPO LÓPEZ, J. Mitos y creencias en los procesos de cambio en América Latina. ZEA, L. América Latina en sus ideas. Coordinación e introducción por Leopoldo Zea. México: UNESCO - Siglo XXI,1986.

OSPINA, W. "Guayacanal. Entrevista". Disponible en: https://www.semana.com/cultura/articulo/william-ospina-habla-con-semana-de-su-nuevanovela-guayacanal/618782. 
RICHARD, N. Fracturas de la memoria: Arte y pensamiento crítico. Buenos Aires: Siglo XXI Editores Argentina, 2007.

RICOEUR, P. La memoria, la historia, el olvido. Traducción de Agustín Neira. Buenos Aires: Fondo de Cultura Económica, 2004.

RIVAS, L. La novela intrahistórica y el Caribe hispánico en la ficción femenina. Estudios. Revista de Investigaciones Literarias y Culturales. N. 18, 2001.

TIEDEMAN, R. Introducción. BENJAMIN, W. Libros de los pasajes. Edición de Rolf Tiedeman. Traducción de Luis Fernández Castañeda. Madrid: Ediciones Akal. 2005.

TRELLES PAZ, D. El futuro no es nuestro. Narradores de América Latina nacidos entre 1970 y 1980. http://www.piedepagina.com/

YEHYA, N. "introducción". TRELLES PAZ, D. El futuro no es nuestro. Narradores de América Latina nacidos entre 1970 y 1980. Disponible en:

http://www.piedepagina.com/redux/04/08/2008/dinamitar-la-propiedad-ajena/

UNAMUNO, M. Obras Completas. T VIII. Edición de Ricardo Senabre. Madrid: Fundación José Antonio Fernández de Castro, 2007.

Recebido em: 31/10/2019. Aceito em: 15/01/2020. 